\title{
Application of Organosilicon Compounds for Improving Moulded Peat Quality
}

\author{
Vladimir Belyakov ${ }^{1}$, Alexsandra Kuporova ${ }^{1}$ \\ ${ }^{1}$ Tver State Technical University, A. Nikitin Street 22, 170026, Tver, Russia
}

\begin{abstract}
The results of experiments on drying moulded peat modified hydrophobically with water-soluble organosilicon compounds are presented. A theoretical and experimental analysis has found that a hydrophobic agent increases the efficiency of the moulding process while reducing the degree of mechanical peat mass dispersion. When the optimum concentrations of additives are maintained, a significant increase in strength is observed with the same drying intensity.
\end{abstract}

\section{Introduction}

The peat industry is currently experiencing a deep recession despite the preserved infrastructure, scientific, technical and ecological potentials [1-4]. The use of peat fuel is conditioned by a number of its advantages over long-range energy carriers (coal, oil, fuel oil, shale) and is second only to gas.

Nevertheless, Russian and foreign investors are beginning to show some interest in peat. Earlier, the Government of the Russian Federation adopted a targeted program (FTP) Energy Efficient Economy for 2002-2005 with an outlook to 2010 (No. 796 of 17 November 2001). The energy strategy of Russia for the period up to 2020 (28 August 2003) was approved where the importance of optimal use of renewable energy sources and local types of fuel is noted. In this regard, the strategy of using peat in the fuel and energy complex is to reduce the consumption of non-renewable resources and reduce burden on the environment from the fuel and energy complex activities.

The development of 1 ha of peat deposits is known to be equivalent to a tree plantation clearance for fuel on 50-100 ha area. Therefore, the development of peat-mining and processing sectors of production should be carried out by the regions together with federal authorities on a corporate basis with leading sectors of gas, oil, forest and other economically developed complexes [5-7], federal and regional target programs being taken into account.

Directions of peat and peat product use in various industries, municipal sector and agriculture are driven by market demand on a specific product and an appropriate technology of its production.

The multicomponent physical and chemical composition of peat feedstock predetermines its use in producing a wide range of products for various industries. Almost complete exclusion of peat from the Russian Federation energy market and the low capacity of domestic agricultural producers to pay necessitate the development of new alternative trends of its use. The priority role in the research belongs to production technologies using deep chemical processing of peat feedstock. 
The application of a hydrophobization principle in peat production is of particular relevance for a number of reasons [8-10]. Firstly, it allows you to indefinitely increase the shelf life of finished products and transportation period over long distances without losing its physicochemical properties. Another important prerequisite for research in this area is the fact that products with hydrophobic additives have low water absorption which gives a number of advantages in its field production.

\section{Materials and Methods}

The purpose of using a hydrophobic agent in the experiments is to obtain high-quality moulded peat products. However, in this case the modifier introduced into peat mass should affect the property of the feedstock and the finished product accordingly, since it changes a priori mass transfer and structure-forming processes in drying [11-13]. The peat production technology generally has two ways to apply a modifier: surface and volumetric. The volumetric peat mass modification during moulding makes it possible to obtain sods with a strong internal structure. This results from the fact that the modifier introduced into the system allows intermolecular and interaggregate interactions in peat to be increased.

This research also uses the method of volumetric peat mass modification followed by its moulding on a screw extruder with a maximum shear stress close to the upper limit of plasticity $(5-5.5 \mathrm{KPa})$. A single-tube cylindrical die is used as a moulding nozzle (Fig. 1).

Due to the rather complicated process of uniform hydrophobic modifier distribution in peat mass the following method of its preparation and moulding was used [14-15].

Native peat (high-moor, decay degree $R_{t}=35 \%$, Kurovskoye peat deposit, the Tver Oblast, Staritsky district) was brought to the pulp state in laboratory conditions. Further, aqueous sodium methylsiliconate was added. Then the feedstock was dried at $T=22-25^{\circ} \mathrm{C}$ and relative air humidity $\varphi=75-85 \%$ to the water content suitable for moulding. Test and experimental sample parties (60 pcs. each), with a sample diameter and length being $40 \mathrm{~mm}$ and $60 \mathrm{~mm}$ respectively, were moulded from the prepared mass. The experimental samples showed the mass concentration of an active hydrophobic agent to be $1 \%$, calculated in terms of absolutely dry substance. The accepted concentration value is justified by a preliminary economic calculation of the technology moulding peat-based solid fuels.

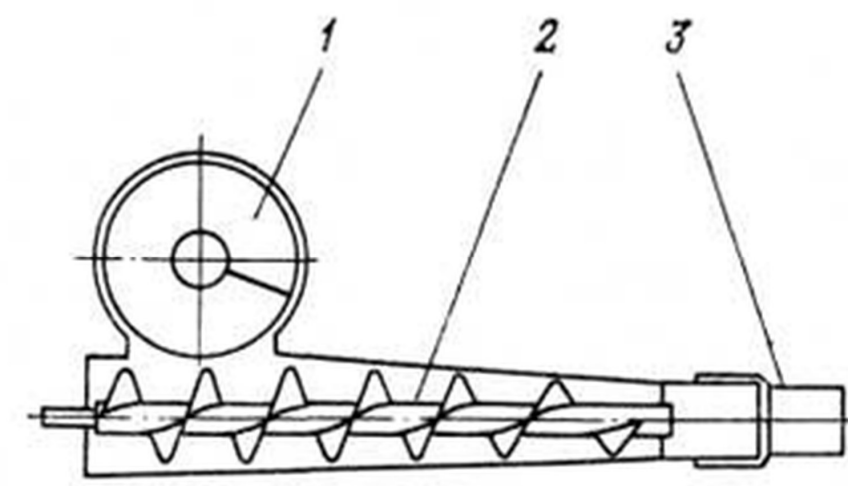

Fig. 1. Schematic Diagram of Screw Moulder. 1 - Pressure Screw, 2 - Delivery Screw, 3 - Die 
The moulded samples were subsequently dried on metal trays at the parameters mentioned above. In drying their size, weight loss, and unconfined compressive strength were determined daily.

It was established experimentally that a modifier added increased peat mass plasticity when the initial water content of moulding was reduced. In such a case, a lower degree of mechanical peat mass dispersion is required before moulding. This will be used by the technology to reduce the energy intensity of the process. At the same time the modifier does not have a significant effect on the drying intensity (Fig. 2) although some experiments showed a slight speed increase by $5-10 \%$. Due to the problems of result reproducibility this fact requires additional verification.

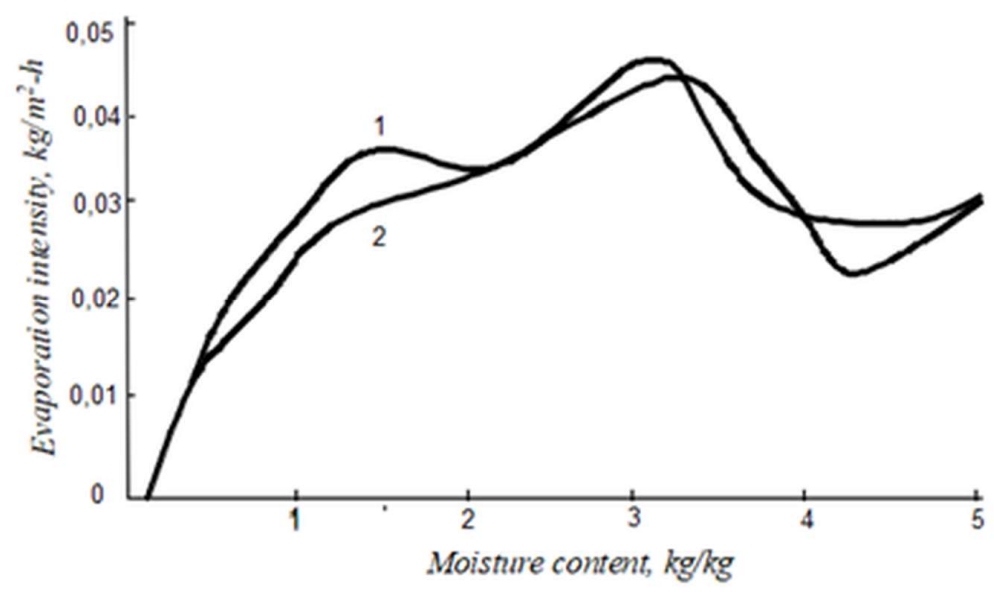

Fig. 2. Dependence of the evaporation rate of test (1) and experimental (2) moulded peat samples

The greatest effect of hydrophobic modification was produced on the moulded peat strength (Fig. 3)

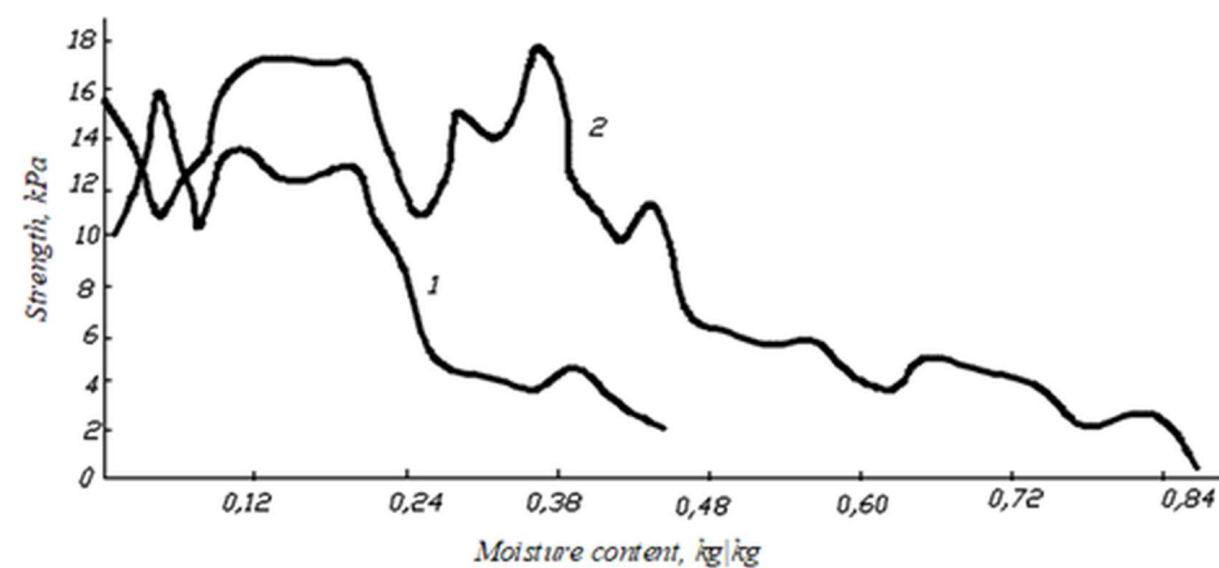

Fig.3. Comparative assessment of test (1) and experimental (2) moulded peat sample strengths 


\section{Results and Discussion}

Sod peat is a solid household fuel for energy industry and utilities as well as a feedstock for deep chemical processing. Moulded peat used as a household fuel can be produced by a variety of ways: by excavating, milling, pressing milled peat in factory (briquetting) and field (semi-briquetting) conditions as well as pelleting with preliminary artificial finish drying. All these methods use pure peat without any additives.

Since the second half of the 20th century the new production of moulded composite peatbased fuel with various organic additives and by modifying peat structure chemically has been developed. In the 1980s the influence of surface-active substances (surfactants) and other high-molecular compounds (HMC) on the formation of water-resistant structure and mechanical strength of peat soil aggregates was studied. Their findings showed that hydrolyzed polyacrylonitrile can be used as a structure former of peat systems. It is a chemical agent obtained by static polymerization of acrylonitrile in condensate water solvent with sodium hydroxide hydrolysis to follow. In Russia hydrolyzed polyacrylonitrile was first used in 1961 to reduce the filtration of fresh, lime and low-mineral solutions (up to $5 \% \mathrm{NaCl}$ ).

In previous studies the additive was added in the range of 0.0001 to $0.5 \%$ of dry matter. When the structure-forming effect of surfactants and HMCs was studied, the equal amounts of peat soil were sprayed with additive solutions being agitated. After the water content decreased slightly, strength tests were performed (unconfined compression). It was established experimentally that HMCs can significantly enhance the polymer adsorption in forming coagulation peat structures. This, ultimately, leads to strengthening of materials. However, later these works have not been widely applied due to their complexity and low economic effectiveness.

Organosilicon-based compositions are most effective, durable, and technologically advanced. At the very beginning of organosilicon compound (OSC) chemistry it was noticed that glassware and some materials that were in contact with alkylchlorosilanes lost their ability to get wet. Moreover, they form hydrophobic polymer films on various materials modifying hydrophilic surfaces hydrophobically. These films are quite strongly bound with surfaces of the most diverse chemical compositions. The high film resistance indicates the existence of chemical bonds between an organic siloxane film and a hydrophilic surface whose properties peat also has. Hydrophobic films are obtained with monomer and polymer organosilicon compounds.

However, almost all OSC have a relatively 'loose' structure and cannot hinder the penetration of single water molecules (water vapor). A surface carbon layer begins to function only when moisture is not present in gaseous form but in the form of large agglomerates (the so-called drop-liquid state). This is visually expressed in the form of water repellency.

\section{Conclusion}

The experimental data analysis allows an unambiguous conclusion that the initial strength recorded on a laboratory press $(\approx 2 \mathrm{KPa})$ can be achieved by hydrophobically modified samples at water content of about $W=1 \mathrm{~kg} / \mathrm{kg}$ which corresponds to water content of $50 \%$. In test peat the strength is recorded only from $W=0.36 \mathrm{~kg} / \mathrm{kg}$. An additive is used to reach maximum strength of $18 \mathrm{KPa}$ while in its absence the destruction pressure does not exceed $14 \mathrm{KPa}$. Moreover, such values are obtained only at low water content which is not provided by the technology of sod peat production in field conditions. An indicative zone in this respect is strength alterations in the range of water content from 0.6 to $0.28 \mathrm{~kg} / \mathrm{kg}$. Here, the modified peat strength exceeds the initial value 1.7-4 times. 
The range of less than $0.16 \mathrm{~kg} / \mathrm{kg}$ in this case is not indicative since the relaxation of stresses in samples with such water content almost always leads to increased cracking and, accordingly, difficulties in objective control over their strength.

Thus, this work shows the promise and prospects of hydrophobic modifiers in the production of moulded solid fuels primarily in field conditions. This will not only reduce their dependence on climatic variables but also obtain additional qualitative advantages over traditional approaches.

\section{References}

1. A.E. Afanas'iev, S.N. Gamayunov O.S. Misnikov, Colloid Journal: Kolloidnyi Zhurnal, 61, 3, 274-279 (1999)

2. O.S. Misnikov, O.V. Dmitriev, E.Yu. Chertkova, Eurasian Mining. Gornyi Zhurnal, 2:24, 30-34 (2015)

3. O. Misnikov, A. Timofeev, O. Pukhova, Polymer Science. Series D, 8:1, 66-74 (2015)

4. O.S. Misnikov, O.V. Dmitriev, V.I. Popov, E.Yu. Chertkova, Polymer Science. Series D, 9:1, 133-139 (2016)

5. O.S. Misnikov, Mires and Peat, 21:7, 1-14 (2018)

6. O. Misnikov, E3S Web Conf., 21, 01020 (2017)

7. V. Lebedev, O. Puhova, E3S Web Conf., 15, 01018 (2017)

8. E.A. Kremcheev, D.A. Kremcheeva Indian Journal of Science and Technology, 9:12, 89525 (2016)

9. O. Misnikov, V. Ivanov, E3S Web Conf, 15, 01017 (2017)

10. O.S. Misnikov, A.E. Afanas'iev, Theoretical Foundations of Chemical Engineering, 37:6, 582-589, (2003)

11. O.S. Misnikov, I.O. Korolev, Polymer Science. Series D, 10:3, 255-259 (2017)

12. O. Misnikov, Polymer Science. Series D, 7:3, 252-259 (2014)

13. S.N. Gamayunov, O.S. Misnikov, Inzhenerno-Fizicheskii Zhurnal (IFZh), 71:2, 233-234 (1998)

14. V. Lebedev, O. Puhova, E3S Web Conf., 21, 01023 (2017)

15. V. Lebedev, O. Puhova. E3S Web Conf., 41, 2018, 01049 (2018) 